\title{
On Learning Urban Design
}

\section{Kim Dovey}

This paper comprises a brief review of the range of approaches to urban design pedagogy published in this edition of JUD. Where and how is an understanding of urban design best learnt, using what techniques, theories, databases and technologies? What is the role of fieldwork and of travel? What are the ideal relations of research to teaching and to practice? I argue that good urban design thinking is multi-scalar and multi- dimensional; a key task is to innoculate students against singular explanations. Learning urban design means developing many kinds of critical thinking about how cities work.

The papers published in this edition of JUD open a range of issues and debates about urban design pedagogy. What are the best learning environments for urban design - interdisciplinary laboratories, streets, travel, community workshops? What are the best techniques and technologies for learning urban design? The authors are to be commended in articulating a rich and interconnected cluster of issues; if I am critical in what follows it is in order to further this same task and explore some interrelated concerns.

The paper by Mapua Lim et al. shows how digital technologies can be useful in teaching and learning urban design. A good example is the use of video to bring some older ideas such as Cullen's townscape theory to life as a dynamic kinaesthetic experience rather than the reduction to the picturesque that is such a common prejudice. Too much can be made, however, of "multi-sensory knowledge" and the decline of "text-based literacy". The aura of new technology and the genuine pleasures of the new gadget can produce a confusion of means and ends. Digital technologies are tools for better understanding and transforming the city; they are good at producing information but can also camouflage the difference between information and knowledge.

Moudon's paper is also largely focused upon opportunities that are opened up by digital technologies, in this case the use of large urban databases for PhD research. She argues for an approach that "borrows more directly from the quantitative than the qualitative sciences", placing students within a formal laboratory setting. Doctoral students become part of multidisciplinary teams with access to powerful databases and rich peer-to-peer learning modes. The intellectual benefits here also lie in getting serious about the analysis of urban morphologies, particularly issues of density, functional mix, access networks and walkability at multiple scales. The PhD becomes deeper but potentially narrower as students focus on those dimensions that can be measured. Yet urban design knowledge spans from design methods to the humanities and social sciences as well as the quantitative methods of science it cannot be reduced to a science (Dovey \& Pafka 2016). While Moudon suggests the laboratory model "as an alternative to and not a replacement of the traditional model" the question remains of how multiple models might intersect. She also suggests that enhanced access to big data will "preempt the need for initial field work". The benefit here is huge, but so is the danger that students will substitute the data for the real city, which is surely the real urban design laboratory.

The idea of urban design pedagogy based in immersive fieldwork is fundamental for Loukaitou-Sideris and Mukhija who focus on informal urbanism in North American cities. This paper gives rise to two thoughts. First, since informal urbanism is a kind of DIY urban design why not ask students to design and implement real projects in underutilized and interstitial space - experiment on the real city. Here the university's risk managers may well step in - students are much safer in the library or the big 
databanks, but they may learn more under conditions of risk. The second thought is that the global challenge of understanding urban informality requires travel to cities of the Global South. Travelling studios of this kind can range from the worst kind of slum tourism to an immersive and collaborative experience with quite profound learning outcomes. When such access or travel is not possible, the use of games in the studio can help jolt students out of the top-down design mode and to understand informal urbanism as an incremental adaptive process (Owen et al. 2013).

In her paper 'Citizenship in Action', Kallus also adopts a community design model with a focus on how imagination and visualization can be shared with marginalized communities. Her goal is one of building 'urban citizenship', a particular problem in a place like Israel with such deeply conflicting claims to place identity. Here we find some laudable examples of community engagement where the focus on questions of visualization and imagination becomes crucial. However, a deeper question remains - if genuine citizenship for Palestinians is not possible within an ethnic state such as Israel, then isn't the ideal of 'urban citizenship' a form of false hope? Is there a danger that these imaginative visualizations can become a form of legitimating imagery? If so then what is the scope for urban design in such a context, beyond a deconstructive reduction to text?

Neuman's paper addresses the challenges of multi-disciplinary, multi-scalar, multi-cultural and collaborative problem-based teaching. To what degree should we turn the urban design studio into a research project, and how much might we judge the pedagogy on design outcomes? In the end urban design pedagogy must enlarge the urban imagination and explore the limits of the possible city. Most urban design teachers, however, will also be aware of the opposite problem with students eager to reshape the city with little understanding of how it works. Parametric design (often based on big data) has the capacity to produce seductive but impossible urban images that are often little more than graphic design masquerading as urban design. The paper by Speranza on using parametric design to incorporate data on experiences of place seeks to address this very problem. This is an important issue and while the paper is full of optimism about the potential of the latest software, it does not yet convince.

Urban design, like the city itself, is fundamentally multiple and therefore also subject to multiple pedagogies. A key task is to prevent students from performing any one of the many reductions that are on offer - reduction to phenomenology, big data, discourse analysis, graphic design, parametric design, morphological analysis. The many 'isms' hold the same threat: modernism, post-modernism, participationism, new urbanism, formalism, marxism, deconstructionism. There is no one thing that explains cities, no right way of designing them, no singular urban design pedagogy. All great cities are different. No teaching program can contain all relevant material and the attempt to squeeze it in can dumb it down. The greatest urban design teaching inspires critical thinking and lifelong learning about cities; what happens in universities is just a beginning.

\section{References:}

Dovey, K. \& Pafka, E. (2016) "The Science of Urban Design?" Urban Design International, 21 (1) 110. doi:10.1057/udi.2015.28

Owen, C., Dovey, K. \& Raharjo, W. (2013) "Teaching Informal Urbanism", Journal of Architectural Education, 67 (2) 214-223. 